\title{
Environmental Benefits of Reusable Modular Mass Timber Construction for Residential use in Japan: an LCA Approach
}

\author{
Rafael Novais Passarelli ${ }^{*}$ \\ ${ }^{1}$ Architect, Nikken Sekkei LTD. Architectural Design Department, Japan \\ *Corresponding author's e-mail: architect@ rafaelpassarelli.com
}

\begin{abstract}
The demand for wooden buildings in Japan consistently reaches figures over 50 million square meters per year. However, the building industry in Japan is based on the constant renewal of the building stock, leading to a short average lifespan, and an unsustainable and wasteful system both from the environmental and economic point of view. As an alternative to this situation, this study assesses the environmental benefits of a modular mass timber system using CLT, designed for consecutive reuse. First, the study presents an award-winning proposal for a modular, reusable mass timber system for residential construction in Japan. After, the study calculates the Global Warming Potential of construction (GWP) of the reusable system in comparison to a conventional mass timber system (benchmark), using the Lifecycle Assessment (LCA) method. The study evaluates the proposed system in two different locations, within 60 years. Three different scenarios for forest resources are considered during the above time-frame, namely stable forest (standard), growing forest (optimistic) and decreasing forest resources (pessimist) to understand how changes in the carbon flow of forests could impact the environmental output of the construction. The results show a modular construction system can be used to provide highquality dwellings in Japan leading to a significant potential for mitigating the impacts of construction on the environment. More specifically, a growing forest scenario provides the smallest GWP, more than $100 \%$ smaller than the benchmark.
\end{abstract}

\section{KEYWORDS}

Circular economy; Design for reuse; CLT; Lifecycle Assessment; Global Warming Potential; GHG emissions.

\section{INTRODUCTION}

Despite the low birth-rate and shrinking population, the annual demand for new buildings in Japan is consistently over 100 million square meters, predominantly aimed for residential use (MLIT 2016). Among the total demand for buildings, wood-based building systems have a significant share of the market, reaching about $40 \%$ of the total residential construction starts in 2017 (MLIT 2016). At least two reasons keep the demand for construction high in Japan. First, over the past decades, the population from smaller municipalities moved to large urban centres, mostly around Tokyo and Osaka, thus increasing the demand for residential construction in these regions. Second, the residential building industry in Japan, is based on the constant replacement of the building stock, maintaining a high demand for construction and leading to an overall short average lifespan of houses, estimated in less than 30 years (Koo 2008). As pointed out by Koo 
(2008) this results in a wasteful system both from the environmental and economic point of view, with about 4\% of Japan's GDP is lost annually.

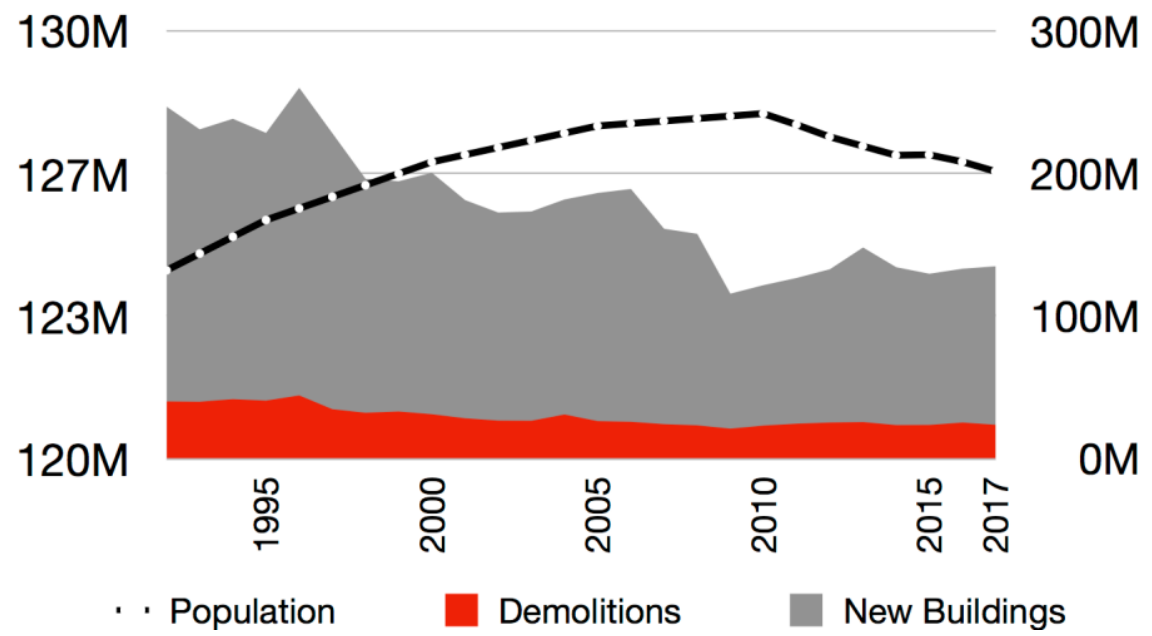

Figure 1. Population change, new construction starts and demolitions in Japan. Source; raw data retrieved from Japan Statistics Bureau, 2018 and visualised by the author.

The literature on the environmental impact of wood-based construction consistently favours wood-based materials in comparison to mineral and metal-based construction such as reinforced concrete or steel (Cole 1998; Gustavsson and Sathre 2006; Petersen and Solberg 2005). More recently, studies that include the assessment of mass timber options such as CLT in construction show the high feedstock energy of the material as the primary source of the potential environmental benefit, provided that incineration of CLT panels for energy generation occur at the end-of-life stage (Robertson et al. 2012; Takano et al. 2015). Nevertheless, the authors also highlight the higher embodied energy content of mass timber systems in comparison to other wood-based systems and even mineral-based ones.

However, as demonstrated by Borjesson and Gustavsson (2000), the correct assessment of the environmental impacts of wood-based products and construction also needs to address different forest land-use scenarios and consider a determined rotation period. In particular, in the case of Japan where wooden buildings have a short lifespan, there is a risk that the high embodiedenergy and material-intensive mass timber systems could lead to an increase in the net GHG emissions and resource depletion if used in the current wasteful system. Conversely, considering the high demand for residential construction and high embodied-energy of mass timber systems, there should be great potential from the environmental point of view for mass timber modular construction if used according to the circular economy concept, defined as a system intentionally designed to be restorative and regenerative (Ellen Mcarthur Foundation 2013) aiming to increase resource use efficiency.

This study focus on a CLT building system designed for disassembly and reuse in construction. Contrary to the usual recycling or energy recovery which downcycles the material, the reuse proposed in this study consider panels can keep serving their original role for an extended time. Hence, even if the lifespan of a determined building ceases after 30 years, the lifespan of the 
materials employed in the building can be extended further and the embodied energy and materials conserved, thus reducing demand for virgin materials.

The study assesses the environmental impacts of a modular mass timber system using CLT, designed for consecutive reuse cycles. It evaluates the benefits of reusing CLT panels for two rotation periods (30 years each) in comparison to the usual energy recovery end-of-life scenario followed by the construction of a new building using virgin materials only.

\section{METHOD}

First, the study describes an award-winning proposal for a modular, reusable mass timber system for residential construction in Japan. The primary goal of this proposal is to allow for an extended service time of building materials used in residential construction in Japan, focusing on reusability, portability and adaptability. The proposal won the Jury prize at the 2015 CLT Idea Contest, promoted by the Japan CLT Association.

After, using the LCA method (Technical Committee CEN/TC 350 2014), the study investigated the environmental benefits of reusing RMMT system for a $33 \mathrm{~m}^{2}$ one-bedroom single-family house in two different locations, within 60 years (30 years for each cycle). The location of the main assembly line was assumed to be in Tokyo, and both use cycles were assumed to be located within a $100 \mathrm{~km}$ radius from the assembly facility to account for all Kanto region. Additionally, an extra $10 \%$ volume for all materials was included between the first and second cycle to account for possible losses during the use, disassembly and transportation stages, except for the foundation, metal fasteners and vapour barrier, which used $100 \%$ virgin materials in both cycles. The study shows the total GWP from modules A1-A4, B-6, C2-C4 and D for load-bearing elements and envelope materials. Impacts concerning the exterior or interior finishings, hydraulic and electric installations are out of the scope of this study. GWP values for each material, defined as $\mathrm{kg} \mathrm{CO} 2$ equivalent, were retrieved from (Bundesministeriums für Umwelt, Naturschutz, Bau und Reaktorsicherheit 2016), and data about average household energy use in Japan from (Jyukankyo Research Institute Inc. 2014) to calculate the impact on module B-6.

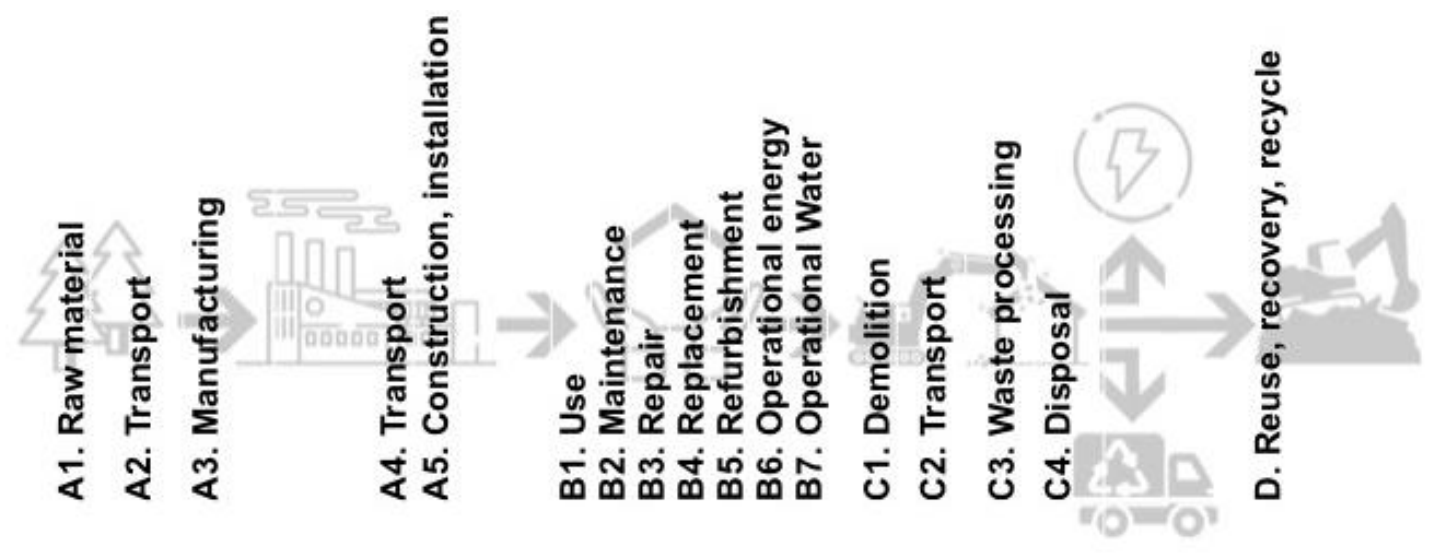

\section{\begin{tabular}{lll|l|l} 
Product & Construction & Use & End-of-life & Benefits, loads
\end{tabular}}

Figure 2. System boundary and assessed modules according to the life cycle stages from EN 15804. 
Following, to understand how changes in the carbon flow of forests could impact the construction, the author modelled three different forest land-use scenarios, to account for the surplus wood in the forest, resulting from the reuse of components instead of harvesting virgin materials. The scenarios modelled are A) stable forest (standard), B) growing forest (optimistic) and C) decreasing forest resource (pessimist). Hence, case A presents a stable forest land-use, meaning the growth and use of resources are in equilibrium; thus the carbon balance ratio is assumed as neutral, and no impact or benefits added to the system. This case represents the standard LCA study. Case B considers a young growing forest, in which the surplus wood serves as carbon stock for the first 30 years. After that, carbon sequestration in Japanese forest stops (Fukuda et al. 2003), thus finishing the carbon storage benefits incorporated into the system as well. Case $\mathrm{C}$ foresees a resource depletion case, meaning a situation in which there is no maintenance in the forest since harvesting, which leads to deforestation. Hence, energy-recovery of wood-based production does not add benefits concerning the GHG emissions. The author calculated the conversion from sawn-timber volume to forest area according to (Han et al. 2016), (Fukuda et al. 2003), and modelled impacts and benefits due to the changes in forest land-use according to the (European Commission - Joint Research Centre - Institute for Environment and Sustentability 2010).

Table 1. Cases summary.

\begin{tabular}{lcc|cc}
\hline & \multicolumn{2}{c|}{$0-30$ years } & & $31-60$ years \\
\cline { 2 - 5 } & Reuse & Additional benefits/impacts & Reuse & Additional benefits/impacts \\
\hline Benchmark & $0 \%$ & None & $0 \%$ & None \\
Case A & $0 \%$ & None & $90 \%$ & None \\
Case B & $0 \%$ & Forest C sequestration benefit & $90 \%$ & None \\
Case C & $0 \%$ & Forest depletion impact & $90 \%$ & Forest depletion impact \\
\hline
\end{tabular}

\section{RESULTS AND CONCLUSIONS}

Main results and conclusions are described as follows.

\section{Reusable modular mass timber building system (RMMT)}

The primary goal of this proposal is to allow for an extended service time of building materials used in residential construction in Japan. The proposed reusable modular mass timber system (hereafter referred to as RMMT system) makes use of CLT planar characteristics and combines its environmental qualities and physical strengths, focusing on three main features, namely reusability, portability and adaptability to achieve the goal above.

Reusability. The RMMT system employs CLT panels as the structural core of prefabricated modules. In addition to the structural role, the core provides air-tightness to the construction and cuts of thermal-bridges. Following, Structural Insulated Panels (SIPs) fixed on the CLT core provide the required thermo-acoustic performance to the house. Finally, the exterior and interior finishing shall be added depending on user or code requirements. Following a principle of design for reuse and interoperability, all elements are fixed by screws and prefabricated based on the dimensions of the CLT core modules respectively, so that they can be disassembled and utilised in different modules. 


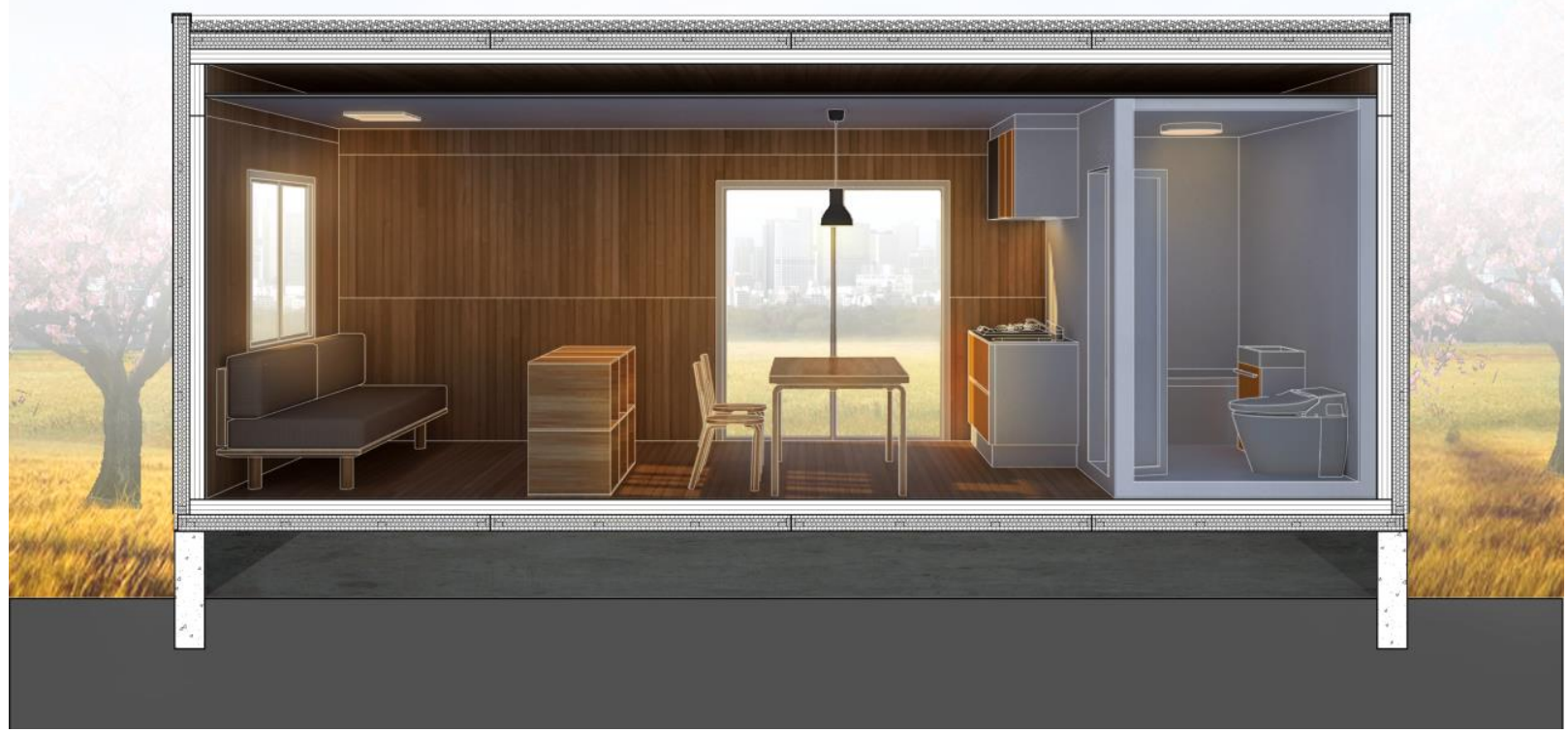

Figure 3. Cross section image of the studio module.

Portability. The RMMT system is compact enough to fit a $20 \mathrm{~m}^{2}$ studio module in one truck when disassembled, thus making it also suitable for disaster relief situations and recovery of areas affected by natural disasters.

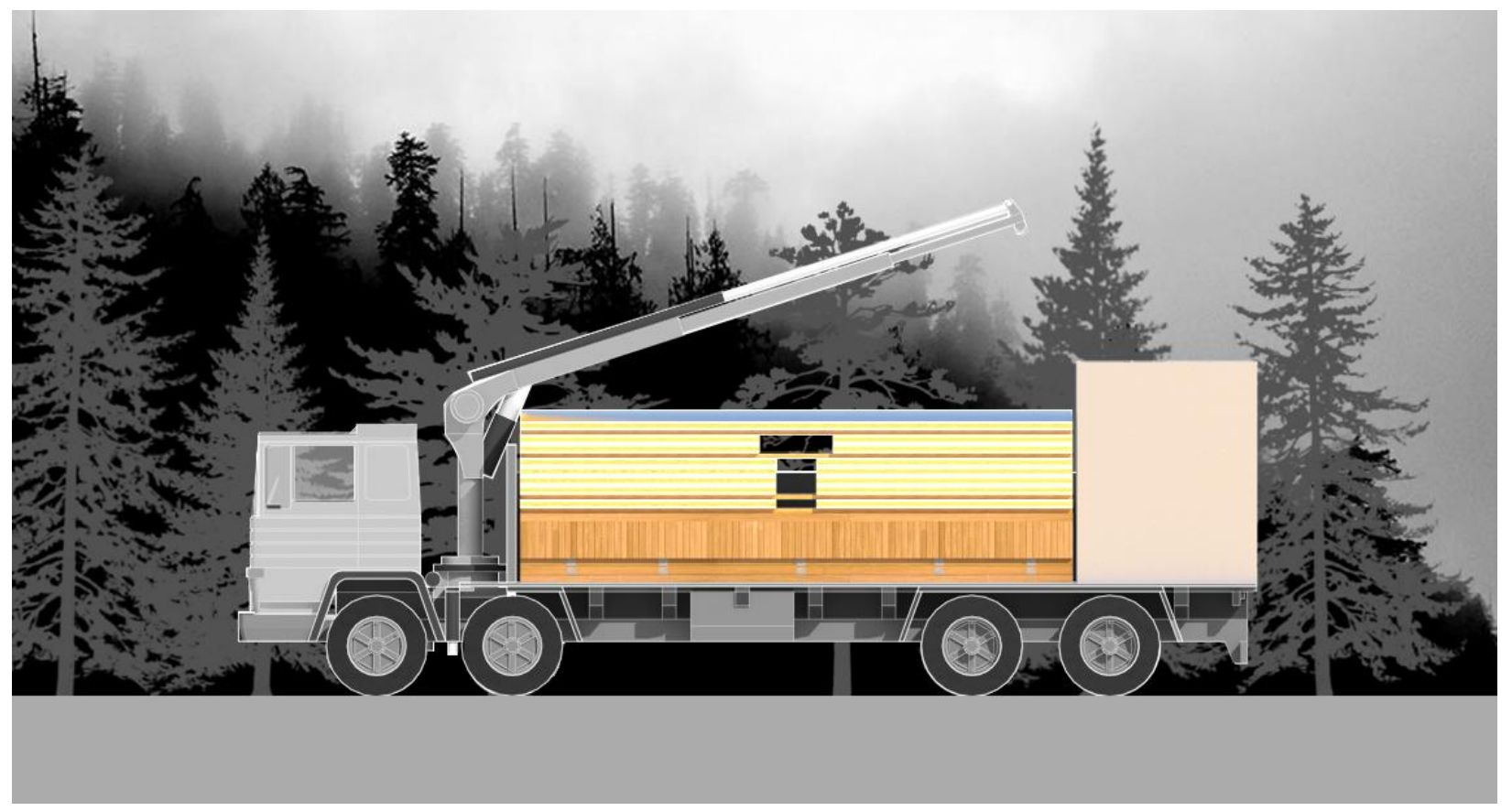

Figure 4. Disassembled studio module loaded on an 8-ton truck.

The assembly method of the CLT core is as follows:

(1) A crane lifts the CLT core from the vehicle. 
(2) The CLT core gradually unfolds into a volume module, forming the core structure of the building.

(3) After the longitudinal walls unfold entirely, the transversal walls slide into the upright position.

(4) Longitudinal and transversal walls are fixed in place by self-tapping screws, and the CLT core is ready to receive the sip panels and finishing materials.
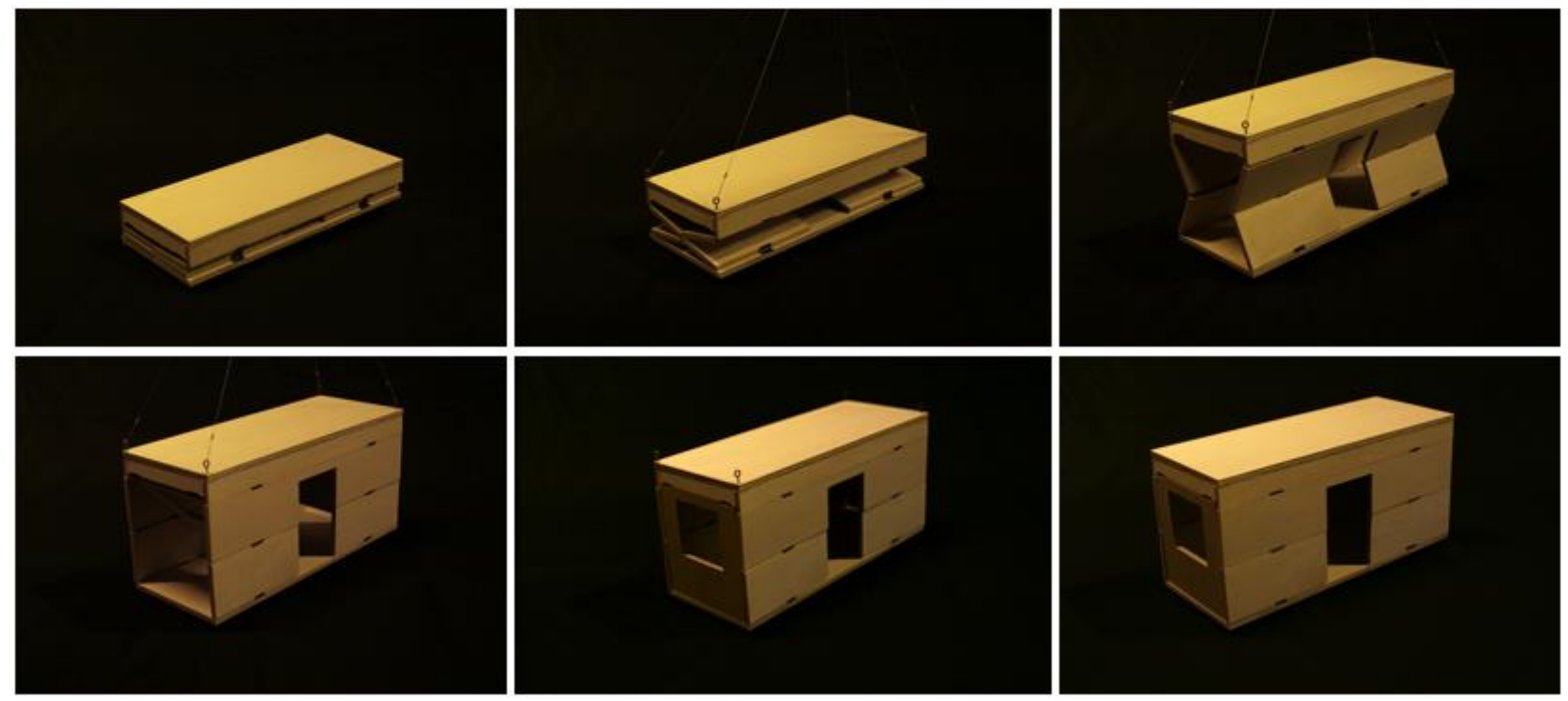

Figure 5. The unfolding sequence for the CLT core.

Adaptability. By combining different modules, the RMMT system can offer several layout options to answer the different needs of different users or changes in lifestyle along one user's lifetime. Also, the modules of the RMMT system could be a "product service system", leased for a predefined amount of time. Then, when the resident moves out, or at the end or termination of the leasing contract, the company that owns the modules disassemble the house and repairs the modules if necessary. Finally, the refurbished modules can be installed at a different place and leased to a new user. To offer houses as a product of service in Japan can be one resourceconscious solution to adapt to the dynamic Japanese building industry as discussed above.
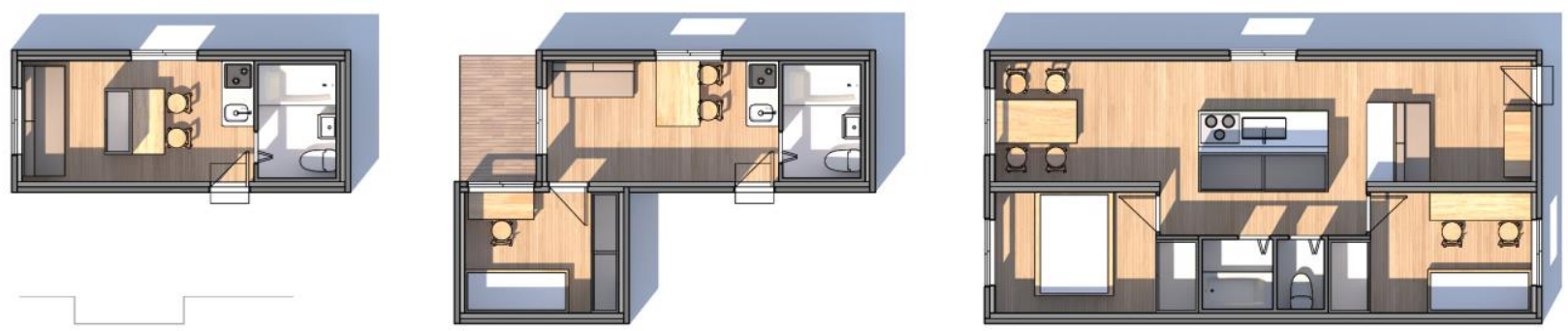

Figure 6. Different plan options for RMMT system. 


\section{Lifecycle Assessment}

The results show the benchmark case at the top, with no reused materials employed and the other cases as a percentage of the benchmark. Figure 7 shows that cases employing reused materials and with stable or growing forest resources present considerably less total GWP than the benchmark with $24 \%$ and $-7 \%$ respectively. On the other hand, Case $\mathrm{C}$ that foresees a pessimist scenario regarding forest resources shows about $70 \%$ more impact than the benchmark case. The influence that forest resource land-use has on GWP is more significant during the first rotation time of 30 years, as larger volumes of virgin resources are needed. On the second rotation period, the benefit of reuse reduced the GWP in Cases A, B, C to 7\%, $7 \%$ and $21 \%$ respectively.

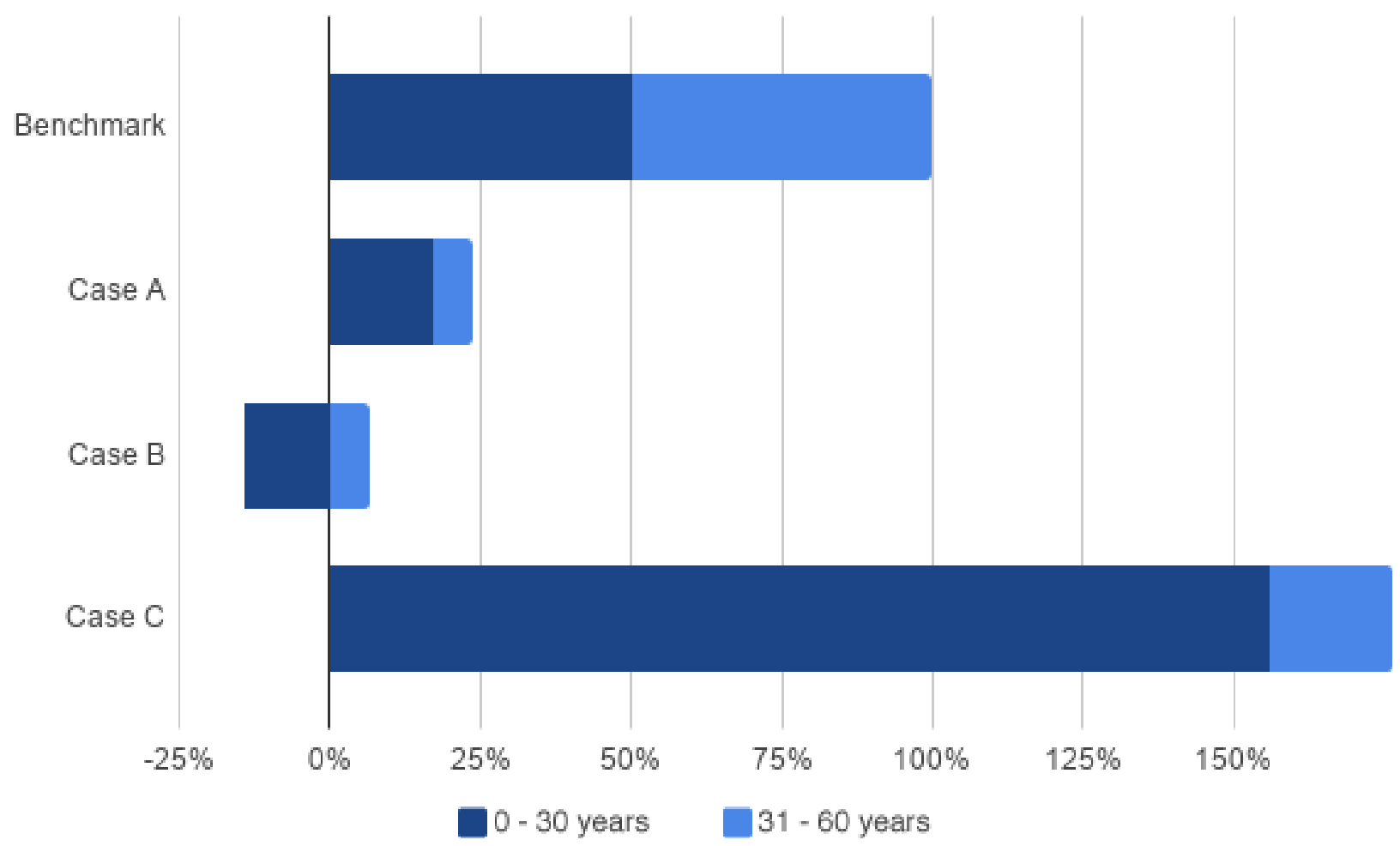

Figure 7. Total GWP of cases as a percentage of the benchmark, by rotation period.

\section{CONCLUSION}

The study presented an award-winning modular, reusable mass timber system proposal aiming to enable an extended service time of building materials used in residential construction in Japan. The results showed modular construction designed for the systematic reuse of main structural materials could lead to a considerable decrease of the GWP of construction. However, the results also revealed the significant influence of the forest land-use on the impacts on construction and made evident that a scenario leading to the depletion of forest resources could result in an increase of GWP. Hence, the crucial need to maintain a stable or growing forest stock in order to make full use of the environmental benefits of timber construction, while exploring the possibilities offered by modular and offsite construction of mass timber technology. 
MOC SUMMIT / MAY 2019

\section{REFERENCES}

Börjesson, P., and Gustavsson, L. (2000). "Greenhouse gas balances in building construction: wood versus concrete from life-cycle and forest land-use perspectives." Energy Policy, 28, 575-588.

Bundesministeriums für Umwelt, Naturschutz, Bau und Reaktorsicherheit. (2016). "ÖKOBAUDAT. Berlin, <http://www.oekobaudat.de> (Nov. 23, 2018).

Cole, R. J. (1998). "Energy and greenhouse gas emissions associated with the construction of alternative structural systems." Building and Environment, 34, 335-348.

Ellen Mcarthur Foundation. (2013). TOWARDS THE CIRCULAR ECONOMY. 1-98. $<$ https://www.ellenmacarthurfoundation.org/> (Dez. 23, 2018)

European Commission - Joint Research Centre - Institute for Environment and Sustentability. (2010). International Reference Life Cycle Data System (ILCD) Handbook. Publications Office of the European Union, Luxemburg, 1-417.

Fukuda, M., Iehara, T., and Matsumoto, M. (2003). "Carbon stock estimates for sugi and hinoki forests in Japan." Forest Ecology and Management, 184(1-3), 1-16.

Gustavsson, L., and Sathre, R. (2006). "Variability in energy and carbon dioxide balances of wood and concrete building materials." Building and Environment, 41(7), 940-951.

Han, Y., Park, J.-H., Chang, Y.-S., Park, Y., Oh, J.-K., Hong, J.-P., Lee, J.-J., and Yeo, H. (2016). "The effect of controlling the drying distortion of laminas on the production yield of cross-laminated timber (CLT) using Larix kaempferi wood." European Journal of Wood and Wood Products, Springer Berlin Heidelberg, 74(4), 519-526.

Jyukankyo Research Institute Inc. (2014). “家庭用エネルギー統計年報 2012 年版.” Tokyo, <http://www.mlit.go.jp/common/001064005.pdf> (Dec. 6, 2016).

Koo, R., and Sasaki, M. (2008). "Obstacles to Affluence: Thoughts on Japanese Housing." NRI Papers, 1-16.

Ministry of Land, Infrastructure, Transport and Tourism (MLIT). (2018). 建築着工統計調査報告. Tokyo, 1-14.

Petersen, A. K., and Solberg, B. (2005). "Environmental and economic impacts of substitution between wood products and alternative materials: a review of micro-level analyses from Norway and Sweden." Forest Policy and Economics, 7(3), 249-259.

Robertson, A. B., Lam, F. C. F., and Cole, R. J. (2012). "A Comparative Cradle-to-Gate Life Cycle Assessment of Mid-Rise Office Building Construction Alternatives: Laminated Timber or Reinforced Concrete.” Buildings, 2(4), 245-270.

Takano, A., Pal, S. K., Kuittinen, M., Alanne, K., Hughes, M., and Winter, S. (2015). "The effect of material selection on life cycle energy balance: A case study on a hypothetical building model in Finland.” Building and Environment, Elsevier Ltd, 89(C), 192-202.

Technical Committee CEN/TC 350. (2014). DIN EN 15804:2012+A1:2013 Sustainability of construction works. Brussels, 1-67. 